\title{
A IDADE DA FAIXA ORÓS: DADOS PRELIMINARES
}

\author{
MARIA HELENA DE FREITAS MACEDO*, JAZIEL MARTINS SÁ* e KOJI KAWASHITA**
}

\begin{abstract}
THE ORós BELT AGE: PRELIMINARY DATA. This paper deals with Rb-Sr whole-rock dates on supracrustal and plutonic rocks of the Orós Belt and their batsement, in the SE corner of Ceará State, Northeastern Brazil. Geologically, the region belongs to the so-called Borborema Orogenic Province, of Brasiliano age. The dated rock units include metavolcanics (rhyolites and dacites) and augen gneisses that intrude them in structural conformity, as well as basement granodioritic orthogneisses. Isochronic dates ca. $1.7 \mathrm{Ga}$ obtained from both the metavolcanics and augen gneisses are regarded as emplacement ages, during the initial phases of basin development. Initial Ro values are quite low, compatible with mantle (or deep-level, $\mathrm{Rb}$-depleted crust) derivation. The age values correlate with those obtained in Chapada Diamantina/Espinhaço (Bahia State) as well as in Hoggar (Algerian Sahara), for middle proterozoic anorogenic igneous-sedimentary sequences. It is proposed that the basin started its development as a middle proterozoic intracratonic rift system, which was much later involved in the Brasiliano (Pan-African) orogenic event. A monocyclic evolution for the Orós Belt is thus favoured. The basement orthogneisses furnished an errorchron of ca. $2.4 \mathrm{Ga}$, regarded as a minimum age of a thermotectonic event in high amphibolite facies, that affected these rocks before deposition of the supracrustal pile.
\end{abstract}

INTRODUÇÃo A Faixa Orós, localizada no SE do Estado do Ceará, está geologicamente situada na Província Borborema (Almeida et al. 1977) e se encontra sobreposta sobre um embasamento arqueano de ampla distribuição na parte central desse Estado. Apresenta-se com uma forma alongada $\mathrm{N}-\mathrm{S}$ com inflexão para NE na porção norte e para WSW nas partes meridionais, formando uma faixa estreita, com largura máxima de $13 \mathrm{~km}$, comprimento de várias dezenas de quilômetros e forma sigmoidal (Fig. 1). As rochas que a compōem são tidas como pertencentes ao Grupo Ceará (Dantas 1974) em substituição ao termo Série Ceará (Crandal 1910, Moraes 1924, apud Gomes et al. 1981). Santos \& Brito-Neves (1984) englobam esta faixa no chamado Sistema Jaguaribeano, interpretando-o como um sistema vestigial formado por unidades vulcanossedimentares nas quais o embasamento estaria extensivamente exposto e as supracrustais estariam restritas a faixas estreitas. Dantas (1974) e Ries (1977) correlacionam o Grupo Ceará às coberturas do Sistema Salgueiro - Cachoeirinha - Serido, porém as feições estruturais e litológicas da Seqüência Orós, a princípio, parecem bem mais simples, principalmente se comparadas com o Grupo Seridó. Os dados geocronológicos para essas faixas dobradas da região do Ceará são escassos e muitas vezes imprecisos, sendo ainda de forte caráter especulativo fazerem-se correlaçōes entre outras faixas da Província Borborema. $O$ objetivo deste trabalho é apresentar alguns dados geocronológicos pelo método $\mathrm{Rb}-\mathrm{Sr}$ efetuados em metavulcanicas e augen-gnaisses plutônicos, além de seu embassamento. É fornecida uma síntese das relaçōes geológicas e sua evolução para uma maior compreensão dos dados aqui expostos.

ARCABOUÇO GEOLÓgico As unidades litológicas Metassedimentos pelítico-psamíticos intercalados por metavulcânicas, intrudidas por augen-gnaisses graníticos, além de metamáfica-ultramáficas, são as principais unidades que compōem a seqüência dobrada da Faixa Orós.

Os metassedimentos são representados por biotita hornblenda gnaisses, quartzitos puros e moscovíticos, e uma seqüência de biotita xistos com granada, podendo conter estaurolita e andalusita. Finas e descontínuas faixas de mármores e carbonatos magnesíferos se encontram intercalados nos micaxistos na porção central desta seqüência.
As vulcânicas são predominantemente félsicas e subordinadamente, em muito menor quantidade, máficas. São volumetricamente dominadas por rílitos porfiríticos, principalmente derrames, com dois tipos texturais: um com textura porfirítica de granulação média, com megacristais de microclínio de milímetros a ate $1 \mathrm{~cm}$, e sills com largura de $10-30 \mathrm{~m}$ e textura porfirítica grossa com fenocristais de quartzo e microclínio de tamanho centimétrico a subcentimétrico. Este último seria o representante subvulcânico desta seqüência. Pórfiros de quartzo azulados são bem visíveis em ambos os tipos. Os metadacitos também ocorrem na área como derrames, intercalados na sequiência de lavas riolíticas. Finas e estreitas faixas métricas, de composição anfibolítica, representam as vulcânicas básicas, sendo comum estas apresentarem ripas bem desenvolvidas de actinolita com textura radial. Tipos de composição intermediária, principalmente tufos com intercalações de metassedimentos, compöem a base desta seqüência descrita (Fig. 1).

Os termos plutônicos que cortam esta seqüência são representados por augen-gnaisses grossos, aflorando na parte este da seqüência com largura em torno de $2 \mathrm{~km}$, e subordinadamente por ortognaisse sienogranítico a fluorita, hornblenda ortognaisses e ortognaisse porfirítico fino de composição granítica, este último aflorante na porção oeste desta faixa. Rochas máfico-ultramáficas constituídas por hornblenda gabros, metamelagabros e hornblenditos também cortam concordantemente a seqüência metassedimentar em forma de corpos alongados, atingindo até centenas de metros de largura.

O embasamento desta seqüência é formado por gnaisses bandados cortados por ortognaisses granodioríticos com desenvolvimento de mobilizados neossomáticos, na parte este, e por gnaisses com extensiva migmatização na parte oeste.

A evolução estrututal É possível identificar nesta cobertura supracrustal um mínimo de três fases de dobramentos denominados de $F_{3}, F_{2}$ e $F_{3}$, tendo sido detectada uma fase de idade prévia $\left(\mathrm{F}_{n}\right)$ à deposição/colocação dessa cobertura nas rochas do embasamento. $F$ desenvolveu uma foliação pouco proeminente, nem sempre distinguível nos afloramentos, năo mostrando um bandamento metamórfico associado, porém pela caracterização de lineação de interseção associada e não paralelismo freqüente de $S_{1}$ com $S_{0}$, visualizam-se dobras fe-

\footnotetext{
* Departamento de Geologia, CCE-UFRN. Campus Universitário, CEP 59000, Natal, RN, Brasil

** Centro de Pesquisas Geocronologicas, Instituto de Geociências, USP. Caixa Postal 20899, CEP 01498, São Paulo, SP, Brasil
} 


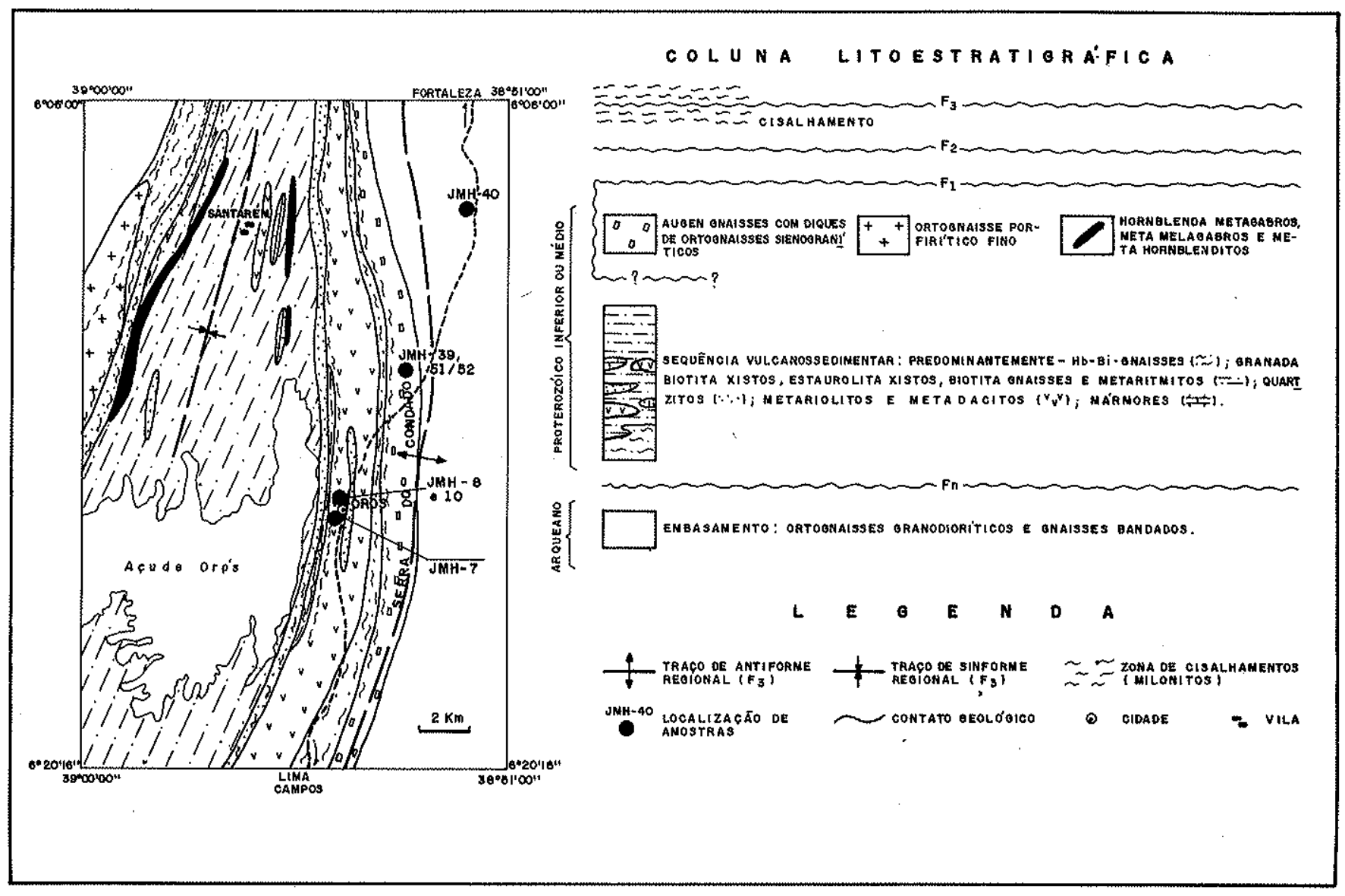

Figura 1-Esbogo geológico e localização das amostras. Regiâo de Orós (CE)

chadas com eixos sempre de mergulho forte, dominantemente para norte. A fase $F_{4}$ desenvolveu a foliação/bandamento metamórfico cartografado na região, sempre proeminente, com dobras isoclinais e transpostas de trend norte-sul c eixos geralmente de baixo ângulo para norte ou para sul. Torna-se difícil definir o macrodobramento $F_{2}$ devido à extensiva transposição auxiliada pelo cisalhamento transcorrente. $F_{3}$ desenvolveu dobras abertas a fechadas, com plano axial de ângulo forte, co-axial ou de baixo ângulo com $\mathrm{F}_{2}$, porém nem sempre apresentando boa foliação de plano axial.

O metamorfismo associado a esses dobramentos atingiu fácies anfíbolito em $\mathrm{F}_{2}$, isógrada da estaurolita, de pressão baixa pela presença de andalusita. $F_{1}$ e $F_{3}$ apresentam características de fácies xisto verde.

$A$ fase $F_{n}$ caracteriza uma discordância tectônica entre o embasamento e estas supracrustais, sendo esta também transposta e sua foliação, por via de regra, paralelizada a $S_{2} . O$ metamorfismo associado a este embasamento atingiu fácies anfibolito alto, tendo desenvolvido feiçōes de mobilizados anatéticos penetrativos nesta unidade, feiçōes estas não observadas nas rochas sobrepostas.

Durante a evolução dessas fases de dobramentos nas supracrustais, características extensivas de cisalhamento foram desenvolvidas, sendo estas feiçōes regionalmente conhecidas como a Zona de Cisalhamento Orós, que está relacionada temporalmente à fase de dobramento $\mathrm{F}_{3}$, tendo porém algumas feições de desenvolvimento desde pré a tardi- $\mathrm{F}_{3}$. Feições de escala meso a microscópicas são abundantes, com critérios cinemáticos que favorecem um movimento dextral, transcorrente. Este cisalhamento está presente em toda a faixa, desde as bordas do embasamento, porém se individualizam regiōes com feiçöes de strain mais elevado. Reportamos-nos à publi- cação de Sá et al. (1987) para uma melhor compreensão da evolução tectonometamórfica da região.

A provável correlação da Zona de Cisalhamento Orós com outros lineamentos do Ceará e do oeste do Rio Grande do Norte, como as falhas de Senador Pompeu, Portalegre e outros seguramente brasilianos como a Zona de Cisalhamento Tauá, por exemplo (Arthaud 1986), não é definitiva como sugere alguns autores (Mello 1984, Arthaud op. cit.), necessitando ainda de um maior acúmulo de informaçôes.

PETROGRAFIA DAS AMOSTRAS DATADAS Foram analisadas pelo método $\mathrm{Rb}-\mathrm{Sr}$ metavulcânicas félsicas (riólitos e dacitos), augen-gnaisses que cortam esta seqüência e ortognaisse granodiorítico do embasamento. Datações futuras de outras unidades serăo necessárias, atê por outros métodos, especialmente U-Pb em zircão, para uma melhor compreensão do significado dos dados obtidos e da evolução desta região.

Foram escolhidas as metavulcânicas e os augen-gnaisses por representarem unidades expressivas na região, com sua situação geologica bem definida, e os ortognaisses do embasamento, por cortarem os gnaisses bandados e caracterizarem uma idade mínima para o embasamento.

Os metadacitos exibem textura porfíítica fina, com megacristais de quartzo e microclínio, matriz fina a média, e composiçāo que varia de riodacito (amostra JMH-10D) a quartzo andesito (JMH-10L). Sempre evidenciam uma boa foliação, denotada pelo estiramento de megacristais e orientação de micas e às vezes anfibólio, como também localmente pelo desenvolvimento de finas faixas milimétricas de cor clara, formando um bandamento metamórfico. Quartzo, plagioclásio, microclínio, biotita, hornblenda e opacos são os minerais essenciais, sendo que nas amostras $\mathrm{JMH}-10 \mathrm{~K}$ e $10 \mathrm{~L}$ a hornblenda e o 
plagioclásio dominam amplamente sobre a biotita e o microclínio, respectivamente. Texturas primárias, como fenocristais hipidiomórficos de plagioclásio e hornblenda, além de golfos de corrosão em quartzo, são observadas.

Epídoto está sempre presente nessas rochas como produto de desestabilização dos minerais presentes, podendo também ocorrer actinolita, clorita e calcita, esta última notadamente na amostra JMH-10A, como veios boudinados. As amostras em geral sẩo frescas, bem preservadas, de coloração cinza-escura, com alguns feldspatos apresentando incipiente alteração, à exceção desta última, com faixas de sericita + calcita + epídoto, intensamente cisalhada, e com veios de quartzo e calcita, identificando-se mesmo planos S, C e C' ligados ao cisalhamento.

Os metarriólitos são representados por dois tipos tectonicamente separáveis no campo. Um com texturas primárias mais preservadas (ponto 8) e outro com feiçōes de cisalhamento intensas (ponto 7), sendo este último analisado no intuito de se obter a idade do cisalhamento. Os primeiros exibem uma textura porfirítica, com pórfiros de microclínio e quartzo azulado bem desenvolvidos, com matriz fina, observando-se ainda feições primárias com alguns cristais de microclínio idiomórficos e quartzo com golfos de corrosão, notadamente na amostra JMH-8F. Os pórfiros de microclínio atingem até $1 \mathrm{~cm}$ e geralmente são maiores que os de quartzo. Cristais de magnetita idiomórficos aparecem em alguns locais visíveis a olho nu. Microclínio, plagioclásio, quartzo, opacos e sericita compōem a matriz, tendo também epídoto, clorita e calcita. Zircões idiomórficos são acessórios sempre presentes. Feições de recuperação de pórfiros de quartzo durante $\mathrm{F}_{2}-$ como também presença de quartzo e microclínio com bordas granulares exibindo textura mortar provocadas pelo cisalhamento pós- $\mathrm{F}_{2}$ - são observadas localmente. Especificamente na amostra JMH-8D, essas feições são bem desenvolvidas, embora na amostra de mão esta característica não se ressalte. Esta última também se apresenta com sericitização mais intensa e é um pouco mais grossa que as JMH-8B e JMH-8F. Mostram coloração creme-amarelada com foliação bem desenvolvida e estiramento principalmente dos pórfiros de quartzo.

As amostras do ponto 7 apresentam composições similares às descritas, porém com texturas miloníticas bem evidenciadas e uma matriz muito fina com quartzo, muita sericita, epídoto e opacos lamelares. Os plagioclásios estão intensamente saussuritizados. Os megacristais de microclínio estẩo quebrados e "cortados" pela foliação milonítica, sendo comuns feições de textura mortar.

Os augen-gnaisses apresentam composiçāo granítica com pórfiros de microclínio às vezes centimétricos se destacando na rocha, de cor cinza-claro a creme. Nas bordas do corpo mostram-se mais estirados, principalmente na borda oeste (Fig. 1), onde efeitos de milonitização se superpōem à deformação regional. No centro do corpo, as feiçōes primárias são mais preservadas com pórfiros idi- a hipidiomórficos de microclínio de onde foram tiradas as amostras analisadas. Localmente neste corpo identificam-se concentrações de anfibólio tipo ferrohastingsita, como também alguns cristais de fluorita.

Nas amostras estudadas, o microclínio domina sobre o plagioclásio e ocorre em quantidades similares com o quartzo, fazendo estes com a biotita a mineralogia essencial da rocha. Apesar de alguns cristais de plagioclásio também se destacarem em tamanho, normalmente fazem parte da matriz. Zircão, apatita, alanita, titanita e opacos são os minerais acessórios, além da clorita. Sempre apresentam biotitas orientadas e quartzo estirados, evidenciando uma trama tectônica na rocha, sendo que nas amostras JMH-51A e 51C uma textura gnáissica está evidenciada, mostrando localmente um bandamento metamórfico em desenvolvimento. É até possível distinguirem-se microclínios e neoformados na matriz atribuídos ao evento $\mathrm{F}_{2}$. Os microclínios sempre exibem geminação albitapericlíneo, com os pórfiros hipidiomórficos, e-os neoformados com textura intersticial. O plagioclásio geralmente está geminado segundo a lei de albita, com composição de oligoclásio cálcico. O quartzo é xenomórfico e normalmente alongado segundo a foliação imposta à rocha. As biotitas às vezes exibem suas bordas com incipiente cloritização, embora as rochas sejam bastante frescas e os minerais, bem preservados. A amostra JMH-52 difere das demais por apresentar como máficos só algumas biotitas, sempre cloritizadas, textura grossa e com microclínio predominando amplamente sobre o quartzo e plagioclásio juntos.

Os ortognaisses analisados afloram na parte oriental cortados discordantemente pelo augen-gnaisse, apresentam composiçảo predominantemente granodiorítica, com variações locais para composição no campo das rochas graníticas, com microclínio em quantidades similares ao plagioclásio (amostra JMH-40G). São rochas de coloração cinza-escura, com bandamento metamórfico e foliação bem desenvolvida, com quartzo, microclínio, plagioclásio e biotitas orientados segundo a foliação principal da rocha. Zircão e apatita são os principais acessórios, tendo ocasionalmente epídoto, sericita e clorita secundários. A textura da rocha é predominantemente eqüigranular granoblástica, com alguns porfiroclastos de microclínio se destacando. O microclínio também exibe textura intersticial e inclusões de biotitas corroídas e quartzo, além de geminação polissintética cruzada. Pela desestabilização de biotita e quartzo para formar microclínio, além de texturas de microclinização nas bordas do plagioclásio e feições de mobilizados neossomáticos, é fortemente sugestivo que primariamente esta rocha tivesse uma composição tendendo a tonalítica antes do evento $\mathrm{F}_{n}$. O plagioclásio freqüentemente está geminado segundo a lei de albita, também mostrando textura intersticial junto com o quartzo. As biotitas desenvolvem palhetas hipidiomórficas milimétricas, algunas vezes concentradas em faixas orientadas paralelas ao bandamento/foliação da rocha. As amostras são frescas, com cristais bem preservados, com alguns plagioclásios mostrando incipiente saussuritização.

MÉTODOS O reconhecimento geocronológico ao longo da Faixa Orós foi proposto tendo em vista os estudos geológicos de detalhe que estão sendo realizados na área pelos autores, bem como devido ao número reduzido de datações até então existentes, visando assim estabelecer idades mínimas de deposição e/ou deformação do embasamento e supracrustais.

Um número relativamente grande de amostras foi coletado, mas só 21 foram retidas para análises radiométricas $\mathrm{Rb} / \mathrm{Sr}$ em rocha total, após seleçāo prévia realizada por estudos macroscópicos e fluorescência de raios X (FRX). Todo o processamento inicial foi executado no laboratório de Geologia da UFRN. As análises geocronológicas foram efetuadas no Centro de Pesquisas Geocronológica (CPGeo) da USP. Os teores de $\mathrm{Rb}$ e Sr totais foram determinados por FRX segundo técnicas preconizadas por Reynolds (1963) e adaptados por Kawashita (1972). Só uma amostra foi analisada pelo método da diluição isotópica (procedimentos técnicos em Kawashita et al. 1974). As análises isotópicas foram efetuadas com espectrômetros de massa da Varian-Mat tipo TH-5 e V.G. 354. Os valores de ${ }^{87} \mathrm{Sr} /{ }^{86} \mathrm{Sr}$ foram normalizados para ${ }^{86} \mathrm{Sr} /{ }^{88} \mathrm{Sr}=$ 0,1194 . Para o cálculo das idades foi utilizado o programa Williamson (1968) para $\lambda_{\mathrm{Rb}}=1,42 \times 10^{-11} \mathrm{anos}^{-1}$ (Steiger \& Jager 1977).

RESULTADOS E DISCuSSÕES Os dados analíticos referentes a todas as unidades datadas estảo expressos na tabela 1 .

A figura 2 mostra os dados relativos aos metadacitos. Das cinco amostras analisadas e provenientes de um único afloramento, quatro constituem uma isócrona de excelente qualidade $($ MSWD $=0,86)$, mostrando uma boa variação da razão 
Tabela 1 - Dados analíticos Rb/Sr em Rocha Total. Região de Orós (CE)

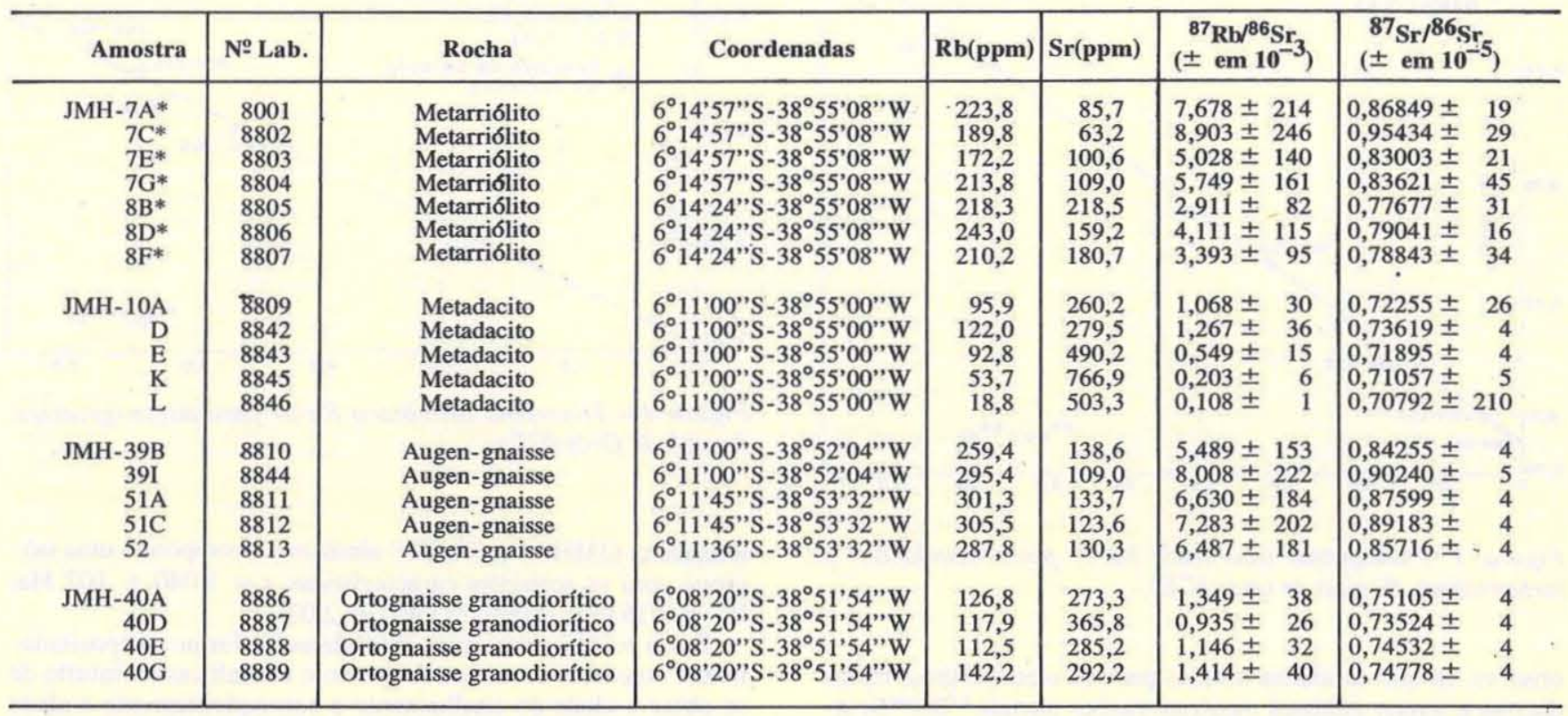

$\mathrm{Rb} / \mathrm{Sr}$, com idade $t=1.707 \pm 46 \mathrm{Ma}$ e Ro $=0,70547$ $\pm 0,00019$.

A amostra JMH-10A, situada abaixo do alinhamento isocrônico, não foi incluída no cálculo da idade. Além de ser texturalmente um pouco diferente das demais, a observação microscópica da referida amostra indica a presença de finos veios de quartzo e calcita boudinados e uma maior quantidade de sericita e epídoto provocada pelo cisalhamento a que foi submetida, perturbando dessa forma seu sistema isotópico $\mathrm{Rb}-\mathrm{Sr}$, o que poderia explicar seu posicionamento fora da isócrona. A idade convencional da amostra JMH-10A $(t=1.185$ Ma para $\left.\mathrm{R}_{\mathrm{O}}=0,705\right)$ é incompatível com as idades convencionais e isocrônica relativas às outras amostras de metadacitos analisadas e não possui significado geológico como resultado da sobreposição de processos tectônicos.

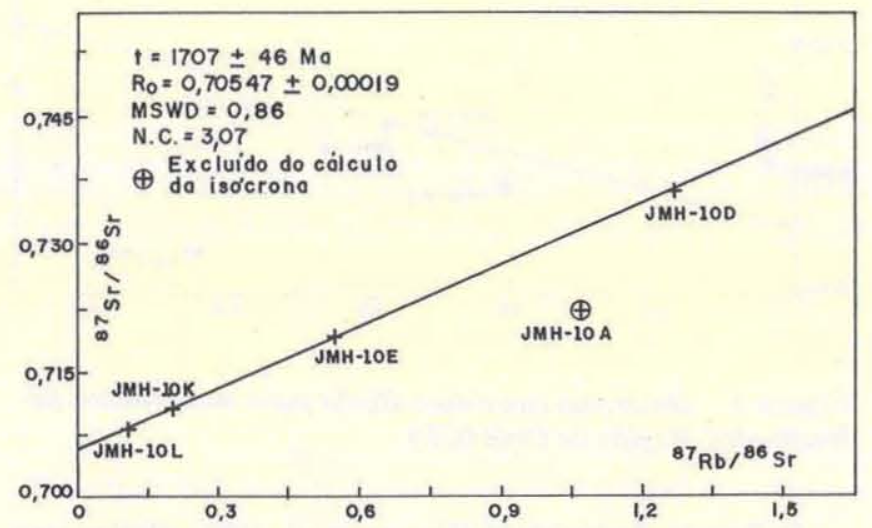

Figura 2 - Diagrama isocrônico $\mathrm{Rb}$-Sr para metadacitos. Região de Orós (CE)

Os metarriólitos foram coletados em dois locais distantes (pontos 7 e 8 , Fig. 1), cerca de $1 \mathrm{~km}$ longitudinalmente, representativos do mesmo derrame de lavas. A amostra JMH-7 mostra-se fortemente milonitizada enquanto a JMH-8 apresenta um strain bem menor. Uma isócrona, contendo todas as amostras analisadas desta litologia, foi tentada, porém sem sucesso. Apesar da grande variação na razão $\mathrm{Rb} / \mathrm{Sr}$, os pontos analíticos representativos das amostras estudadas revelaram-se dispersos. Igualmente, a amostra JMH-8 não constitui uma isócrona. Devem ser considerados neste caso o pequeno número de amostras computadas $(n=3)$; a distribuição inadequada dos pontos analíticos dessas amostras, até mesmo a falta de pontos de controle próximos à origem; e as características petrográficas da amostra $\mathrm{JMH}-8 \mathrm{D}$, que se apresenta mais grossa, com intensa sericitização, estando muito mais alterada que as demais. Este último fato poderia ter provocado abertura do sistema isotópico $\mathrm{Rb}-\mathrm{Sr}$ com perda de ${ }^{87} \mathrm{Sr}$ radiogênico registrando fenômenos de rejuvenescimento isotópico parcial. A idade convencional da referida amostra $(t=1.338$ Ma para $\left.\mathrm{R}_{\mathrm{O}}=0,705\right)$, diferente das demais $(t \cong 1.700 \mathrm{Ma}$ para o mesmo $R_{\mathrm{o}}$ ), vem corroborar com a interpretação acima.

Uma composição da isócrona dos metadacitos com as duas amostras com $\mathrm{Sr}$ menos radiogênico dos metarriólitos do ponto 8 (JMH-8B e 8F) é apresentada na figura 3. Obtém-se, assim, uma nova isócrona, de excelente qualidade, com resultados similares: $t=1.704 \pm 29 \mathrm{Ma} ; \mathrm{R}_{\mathrm{o}}=0,70548$ $\pm 0,00015 ;$ MSWD $=0,43$ e coeficiente de correlação igual a 1 .

A figura 4 mostra os dados representativos dos augen-gnaisses. Estas amostras são provenientes de três afloramentos distintos porém contínuos, com distâncias variando de $500 \mathrm{~m}$ a $1,5 \mathrm{~km}$, mas de um mesmo corpo que constitui a Serra do Condado (Fig. 1). Quatro das cinco amostras analisadas constituem uma isócrona com idade de $1.762 \pm 174 \mathrm{Ma}$; $R_{0}=0,7048 \pm 0,0017$ e MSWD $=0,86 . A$ amostra JMH -52 nẩo foi incluída no cálculo. Esta amostra apresenta as biotitas sempre cloritizadas, indicando possivelmente um processo de retrometamorfismo provocado por um evento superposto, que pode ter desequilibrado o sistema isotópico $\mathrm{Rb}-\mathrm{Sr}$ como resultado da redistribuição desigual e não completa de isótopos de ${ }^{87} \mathrm{Sr}$ em processos posteriores à formação desta rocha.

Analisando os resultados apresentados nas figuras 2,3 e 4, 


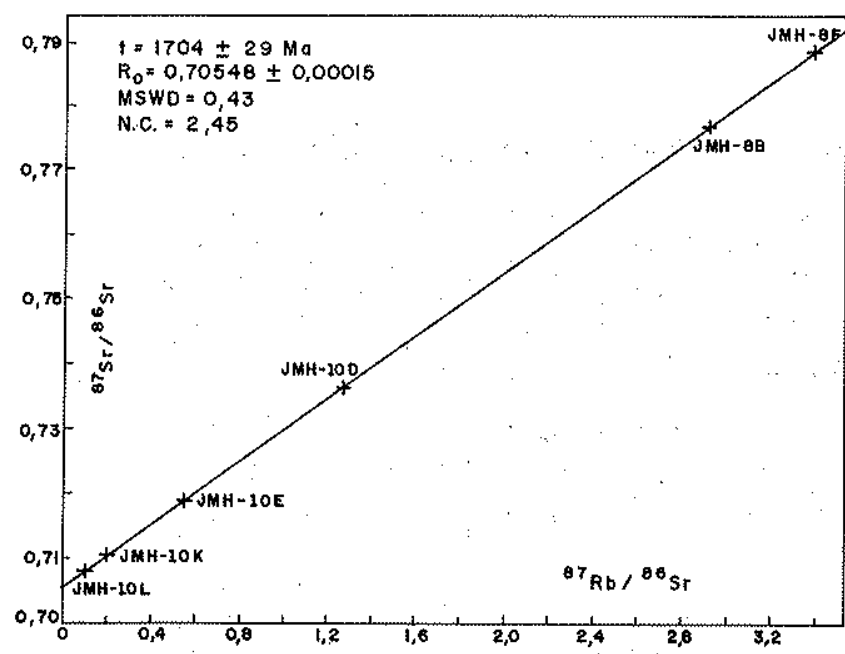

Figura 3 - Diagrama isocrônico $\mathrm{Rb}$-Sr para metadacitos e metarriólitos. Regiāo de Orós (CE)

observa se que as idades obtidas para os metarriólitos, metadacitos e augen-gnaisses mostram razőes iniciais ${ }^{87} \mathrm{Sr} /{ }^{86} \mathrm{Sr}$ similares e idades com torno de 1,7 Ga.

Estes dados podem ser interpretados como idades de cristalização ou como do fechamento do sistema $\mathrm{Rb}-\mathrm{Sr}$ numa época tarditransamazônica, ou ainda representar essas duas hipóteses conjuntamente, considerando-se extrusão/intrusão tarditectônicas ao Ciclo Transamazônico. Os dados de campo não favorecem esta última hipótese, uma vez que não foram observados apófices ou diques dos augen-gnaisses como plano axial de dobras até onde se pode confiar nessas observações como conclusivas.

A primeira hipótese tem a seu favor dataçóes U-Pb realizadas na suíte anarogênica mesoproterozóica do Hoggar (Caby \& Andreopoulos-Renaud 1983), que poderia ser geologicamente correlacionável com a Faixa Orós, com idades similares, como também apresentam as mesmas idades de seqüências vulcânicas ácidas da Chapada Diamantina, que podem ter-se formado num ambiente geotectônico similar à Faixa Orós, ou seja, desenvolvimento de uma bacia pela abertura de um rifte intracratônico.

Supor que esses dados representassem idades de uma orogênese, como aventada na segunda hipótese, implicaria estender o Ciclo Transamazônico até $1,7 \mathrm{Ga}$, o que não é comumente aceito. No entanto, deve-se registrar a existência de propostas da presença de dois ciclos no Proterozóico. Inferior da África: o ciclo Burkinien $(2: 400-2.100 \mathrm{Ma})$ e o Eburnean (2.100-1.600 Ma), este áltimo baseado em idades $\mathrm{Rb}-\mathrm{Sr}$ realizadas em milonitos do oeste da África, que fornecem idades de ate 1:670 Ma (Tempier 1986, Caen-Vachette 1986 e CaenVachette et al. 1984).

As razões iniciais ${ }^{87} \mathrm{Sr} /{ }^{86} \mathrm{Sr}$ dessas rochas em torno de 0,705 são compatíveis com rochas derivadas de fusão do manto com alguma contaminação crustal : e ao mesmo tempo, como os valores são similares, sugere fortemente que essas unidades são co-genéticas, indicando que as vulcânicas, subvulcânicas e as plutônicas são oriundas de mesma fonte.

$\mathrm{Na}$ falta de dados químicos para uma caracterização do ambiente geotectônico de colocação dessas rochas, além de outras análises por outros métodos, U. $\mathrm{Pb}$, por exemplo, essas hipóteses ainda ficam em aberto.

A figura 5 apresenta o diagrama isocrônico relativo às amostras dos riólitos do ponto 7. Três das quatro amostras

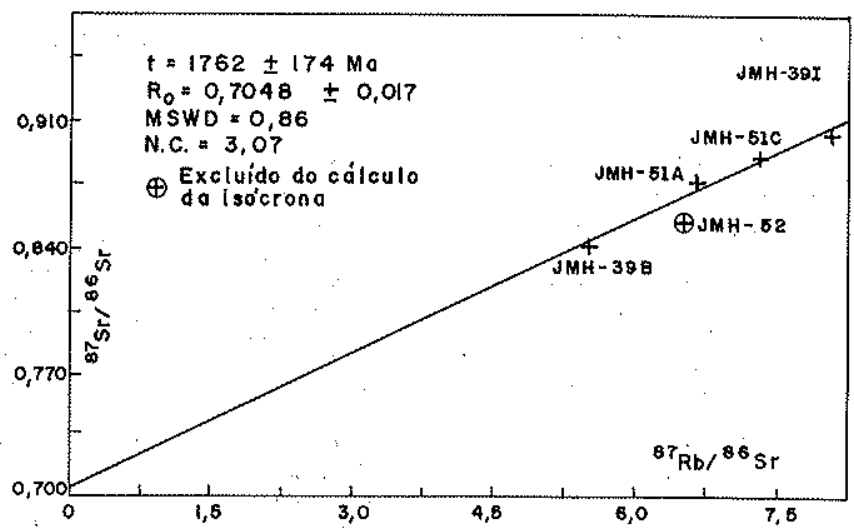

Figura 4 - Diagrama isocrônico $R b$-Sr para augen-gnaisses. Região de Orós (CE)

analisadas (JMH-7A, 7E, 7G) alinham-se compondo uma isócrona com as seguintes características: $t=1.040 \pm 102 \mathrm{Ma}$; $\mathrm{R}_{\mathrm{o}}=0,7535 \pm 0,009 ; \mathrm{MSWD}=2,07$.

Essas rochas, conforme já explanado, foram propositadamente coletadas em zonas fortemente miloníticas no intuito de se obter a idade do cisalhamento e conseqüentemente a idade da Zona de Cisalhamento Orós. A amostra JMH-7C, que foi excluída do cálculo, textural e microscopicamente não mostra diferença das demais com as feiçöes miloníticas bem evidenciadas. A amostra JMH-8D, colocada no referido diagrama isocrônico a título de ilustração, ratifica que a mesma sofreu abertura do sistema $\mathrm{Rb}-\mathrm{Sr}$ provocada pelo mesmo evento. Outros lineamentos do Ceará e do extremo oeste Potiguar, como já citado, são atribuídos como tendo se desenvolvido no Ciclo Brasiliano (Arthaud op. cit.) e podem ser contemporâneos à Zona de Cisalhamento Orós.

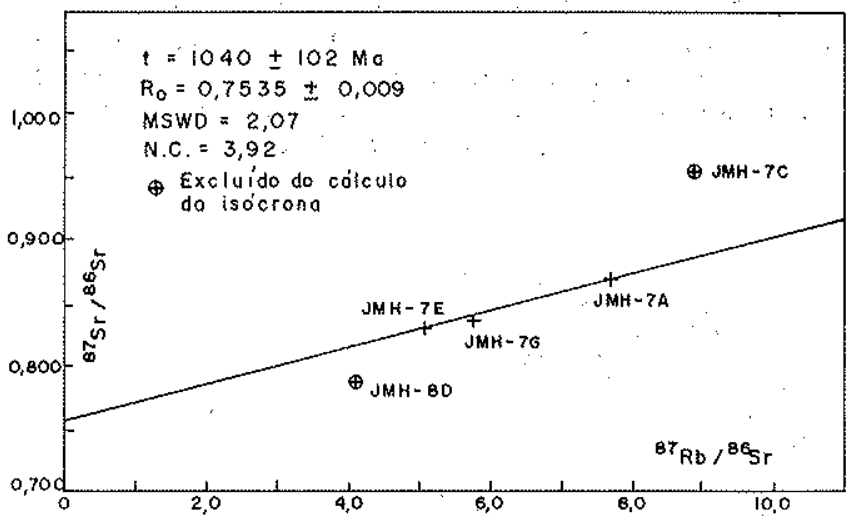

Figura 5 - Diagrama isocrônico Rb-Sr para metarriólitos milonitizados. Região de Orós (CE)

O Projeto Radambrasil (Gomes et al. 1981) obteve uma isócrona de referência ( $\mathrm{Rb}-\mathrm{Sr}$ ) em xistos da região de Orós e adjacências, apresentando dois alinhamentos com idades de 700 a 950 Ma e $R_{o}$ de 0,755 a 0,748 , como também analisou hornblendas pelo método K-Ar de gnaisses do Grupo Ceará, indicando valores em torno de $500 \mathrm{Ma}$. Apesar dos problemas de aplicação do método $\mathrm{Rb}-\mathrm{Sr}$ para metapelitos levantados por McReath \& Sá (1979), por exemplo, esses valores são indicativos do rejuvenescimento isotópico dessas rochas durante 
o ciclo brasiliano, com o valor de $500 \mathrm{Ma}$, representando o final da atuação deste ciclo.

Adicionalmente a esses dados, em supracrustais possivelmente correlacionáveis, no extremo oeste do Rio Grande do Norte, Sá et al. (1986) obtiveram isócronas de leucogranitos e metavulcânicas de idade brasiliana.

Kawashita et al. (1976) obtiveram em migmatitos do Grupo Ceará da região de Banabuiú-Quixadá (CE) idades $\mathrm{Rb}-\mathrm{Sr}$ em torno de $2.020 \mathrm{Ma}$. Estas rochas, porém, seguramente não são correlacionáveis com a Faixa Orós. Esses autores também obtiveram, pelo mesmo método, uma isócrona em quartzomonzonitos que cortam esses migmatitos apresentando um valor de $570 \mathrm{Ma}$, comprovando a atuação do Ciclo Brasiliano nesta região. Ressalta-se que valores similares a estes últimos foram obtidos para aqueles migmatitos pelo método K-Ar.

Desta forma, os valores obtidos e mostrados na figura 5 , apesar de exibirem um alinhamento isocrônico, não têm significado geológico, tendo o sistema $\mathrm{Rb}-\mathrm{Sr}$ sido afetado pela extensiva recristalização dos planos miloníticos, mostrando apenas uma idade intermediária entre $1,7 \mathrm{Ga}$ e o ciclo brasiliano. Esta conclusão também é corroborada pelo elevado valor de $\mathrm{R}_{\mathrm{o}}$, anomalamente alto em comparaçấo com rochas da mesma litologia não milonitizadas, além de não haver justificativa para o ponto JMH-7C não se ajustar na reta, mostrando assim que a boa qualidade deste alinhamento é meramente fortuita. Análises $\mathrm{K}-\mathrm{Ar}$ dessas rochas poderão definir a idade do cisalhamento com mais precisão.

$\mathrm{Na}$ figura 6 estão sumarizados os resultados referentes aos ortognaisses granodioríticos. Os quatro pontos representativos dessas amostras caracterizam uma errócrona cuja idade é de $2.437 \pm 219 \mathrm{Ma}$ para $R_{\mathrm{o}}=0,7025 \pm 0,004$. As amostras apresentam-se migmaiizadas, o que pode ter levado à má qualidade do alinhamento das mesmas no diagrama isocrônico.

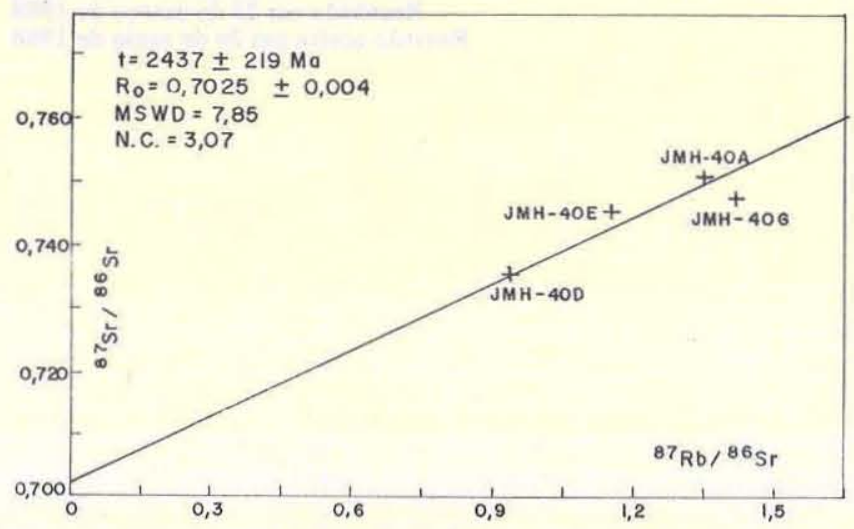

Figura 6 - Diagrama isocrônico Rb-Sr para ortognaisses granodioríticos. Região de Orós (CE)

Achamos porém que, embora possam haver pequenas modificaçōes com a obtenção de dados analíticos adicionais, os novos resultados não mostrarão valores diferentes dos aqui apresentados. Dentro dos limites de erro, o valor obtido é comparável ao encontrado por Pessoa et al. (1986) em rochas similares do embasamento arqueano da regiāo de Tróia, na parte central do Ceará. A baixa razão inicial ${ }^{87} \mathrm{Sr} /{ }^{86} \mathrm{Sr}$ é compatível com a derivação desses ortognaisses como sendo de fonte mantélica.

CONCLUSÕES

Os dados obtidos das metavulcânicas e metaplutônicas intrusivas na seqüência Orós evidenciam para essas rochas uma idade mínima de 1,7 Ga.

Em comparação com outras faixas dobradas da Província Borborema, a evolução estrutural da seqüência Orós nos parece bastante simples, não se evidenciando tectônica de empurrão com posterior transcorrência, a exemplo do que é observado na Faixa Seridó, mais bem estudada, e tida como de desenvolvimento policíclico (Transamazônico e Brasiliano). No momento é mais viável aventar uma evolução monocíclica brasiliana para esta região, tendo as fases $\mathrm{F}_{1}, \mathrm{~F}_{2}$ e $\mathrm{F}_{3}$ se desenvolvido durante este ciclo, uma vez que os dados existentes são indicadores de que a fase $\mathrm{F}_{3}$, intimamente relacionado ao cisalhamento transcorrente da Faixa Orós, foi desenvolvida nesta orogênese.

De acordo com os dados iniciais obtidos neste trabalho, e em consonância com os dados preexistentes e citados do Hoggar e da Chapada da Diamantina, é possível propor para a evolução da Faixa Orós como tendo começado no início do Proterozóico Médio, com o desenvolvimento de uma bacia intracratônica por rifteamento, com vulcanismo predominantemente ácido associado, representado por lavas riolíticas e dacíticas derivadas de fusão mantélica, além de tufos, constituindo a parte basal da seqüência. Estas são sucedidas por uma sedimentação predominantemente pelítica-psamítica com carbonatos subordinados. Posteriormente ou no final da deposição desta seqüência vulcanossedimentar, ocorreram intrusões das plutônicas, podendo também as metamáficas-ultramáficas terem-se instalado nesta época.

No Proterozóico Superior, estas rochas foram submetidas a processos deformativos em regime dúctil, culminando com uma tectônica transcorrente dextral durante oCiclo Brasiliano.

A deposição desta bacia se processou sobre um embasamento possivelmente de idade arqueana, representado por gnaisses bandados e ortognaisses granodioríticos já migmatizados antes dos processos de rifteamento.

Colocada a Faixa Orós neste quadro, é possível fazerem-se na regiāo correlações com os terrenos do extremo oeste do Rio Grande do Norte, descritos por Sá et al. (1986), havendo condições de aventar que aqueles terrenos foram depositados no início do Proterozóico Médio, sendo então o valor de 860 Ma obtido para aquelas metavulcânicas uma idade sem significado geológico, tal qual a aqui apresentada na figura 5. Por outro lado, ainda é incerta sua correlação com o Grupo Ceará na regiảo de Independência por suas marcantes diferenças.

Queremos porém ressaltar que estamos admitindo que as fases $\mathrm{F}_{1}$ a $\mathrm{F}_{3}$ descritas são de um único ciclo, havendo no entanto possibilidade de $\mathrm{F}_{2}$ e $\mathrm{F}_{3}$ serem bastante diferentes no tempo, o que mudaria esta evolução para um quadro policíclico. Para uma maior clareza e segurança desta evolução, tornam-se necessárias, e estão programadas, novas datações destas e de outras litologias por $\mathrm{Rb}-\mathrm{Sr}$ e por outros métodos como também caracterização de suas afinidades geoquímicas, para uma compreensão global e segura desta faixa, e comparações com outras faixas da Província Borborema e da África ocidental.

Agradecimentos Ao CNPq (processo no 40.1732/86) e a Finep/PADCT (processo no 42.86.0405.00), pelo auxílio financeiro; ao Centro de Pesquisas Geocronológicas da USP, pela utilização de seus laboratórios; ao CT/UFPE, na pessoa do Dr. H.S. Villaroel Leó, pela utilização do laboratório de fluorescência de raios X; ao professor E.F. Jardim de Sá, do DG/UFRN, pelas proveitosas discussões; ao motorista Domingos dos Ramos da Silva, pelo forte apoio na coleta das amostras; e ao laboratorista Pedro Ferreira Alves, pela preparação mecânica das amostras, os autores agradecem sinceramente $1: 12$ ajuda, sem a qual este trabalho não teria sido realizado. 


\section{REFERÊNCIAS BIBLIOGRÁFICAS}

ALMEIDA, F.F.M.; HASUI, Y.; BRITO-NEVES, B.B.; FUCK, R.A. 1977. Províncias estruturais brasileiras. In: SIMP. GEOL. NORDESTE, 7, Campina Grande 1977. Atas... Campina Grande, SBG, p. 366-391.

ARTHAUD, M.H. 1986. A falha de Tauá (CE): zona de cisalhamento dúctil de alto ângulo de rejeito múltiplo. In: CONG. BRAS. GEOL., 34, Goiânia 1986. Anais... Goiânia, SBG. p. 766-769.

CABY, R. \& ANDREOPOULOS-RENAUD. U. 1983. Age à $1800 \mathrm{Ma}$ du magmatisme sub-alcalin associé aux métasediments monocycliques dans la chaîne pan-africaine du Sahara Central. $J$. Afr. Earth Sci., 1(3/4): 193-197.

CAEN-VACHETTE, M. 1986. Apport de la geochronologie isotopique à la connaissance du proterozoïque inferieur da l'Afrique de l'Ouest. Centre Int. pour la Formation et les Echanges Géologiques, Paris, 10:25-44.

CAEN-VACHETTE, M.; TEMPIER, P.; CAMIL, F. 1984. Age Rb/Sr 1670 M.a. pour les mylonites de l'accident du Sassandra (Côte d'Ivoire), consequence pour la datation des mouvements fini-éburnéens dans le craton ouest-africain, J. Afr. Earth Sc., 2(4):359-363.

CRANDAL, R. 1910. Geografia, geologia, suprimento d'água, transporte e açudagem nos estados orientais do nordeste do Brasil. Ceará, R.G. do Norte, Paraíba. Fortaleza, Insp. Obras Contra Secas. v. 4. $131 \mathrm{p}$.

DANTAS, J.R.A. 1974. Carta Geológica do Brasil ao milionésimo - fo thas Jaguaribe (SB-24) e Fortaleza (SA-24). DNPM, Brasília, 95 p.

GOMES, J.R.C.; GATTO, C.M.P.P.; SOUZA, G.M.C. de; LUZ, D.S. da; PIRES, J.L. TEIXEIRA, W.; FRANÇA, F.A.B. de; CABRAL, E.M.A.; MENOR, E.A.; MONTEIRO, N.; BARROS M.J.G.; RIBEIRO, E.G.; LIMA, E.A.; FONSECA, R.A. da 1981. Geologia. In: Projeto Radambrasil, folhas SB-24/25 Jaguaribe-Natal; Geologia, geomorfologia, pedologia, vegetação e uso potencial da terra. Rio de Janeiro, MME/Secret. Geral. p. 27-300 (Lev. Rec. Nat. 23).

KAWASHITA, K. 1972. $O$ método $R b-S r$ em rochas sedimentares. Aplicação para as bacias do Paraná e Amazonas. 111 p. (Tese de Doutoramento, Inst. Geoc. USP).

KAWASHITA, K.; CESAR, H.L.; SCHRADER, G.O. 1976. The behaviour of a solid-source mass spectrometer with a glass tube and age determinations on some rocks from the State of Ceará (Brazil). An. Acad. Bras. Ciênc., 48(1):79-86.
KAWASHITA, K.; MANTOVANI, M.; THOMAZ FILHO, A.; TORQUATO, J.R.; BERENHOLC, M. 1974. Método radiométrico rubídio-estrôncio. Procedimentos das análises no Centro de Pesquisas Geocronológicas da USP. 106 p. (Man. int.).

MELLO, A.A. de. 1984. O padrāo de falhamento do nordeste oriental e algumas tentativas de interpretação. In: CONGR. BRAS. GEOL., 33, Rio de Janeiro 1984. Anais... Rio de Janeiro, SBG. p. $1743-1751$.

REYNOLDS, R.C. 1963. Matrix corrections in trace element analysis by X-Ray fluorescence: estimation of the mass absorption coefficient by Compston scattering. Am. Miner., 48:1133-1143.

RIES, A.C. 1977. Stromatolites in the Ceara Group (Precambrian) in Brazil. In: SIMP. GEOL. NORDESTE, 7, Campina Grande 1977. Atas... Campina Grande, SBG. p. 392-396.

SÁ, E.F.J. de; KAWASHITA, K.; MACEDO, M.H.F.; SÁ, J.M. 1986 Supracrustais monocíclicas no extremo oeste do Rio Grande do Norte. In: SIMP. GEOL. NORDESTE, 10, João Pessoa 1986 Atas... João Pessoa, SBG. p. 62-74.

SÁ, J.M.; BEZERRA, F.H.F.; PEREIRA, R. 1987. Evolução estrutural da Região de Orós-Ceará-Brasil. In: I SIMP. NACIONAL DE ESTUDOS TECTÔNICOS, Salvador. Bol. Res... Salvador. p. 6-8.

SANTOS, E.J. dos \& BRITO-NEVES, B.B. 1984. Província Borborema. In: ALMEIDA, F.F.M. \& HASUI, Y. (coord.) Geologia do Pré-Cambriano do Brasil. São Paulo. Blücher, p. 123-186.

STĒIGER, R.H. \& JAGER, E. 1977. Subcommission on Geochronology: convention on the use of decay constants in geo and cosmochronology. Earth Planet. Sci. Let., 36:359-362.

TEMPIER, P.P. 1986. Le Burkinien: Cycle Orogenique majeur du proterozoïque inferieur en Afrique de l'Ouest. Paris. Centre Int. pour la Formation et les Echanges Céologiques. v. 10, p. 17-23.

WILLIAMSON, J.H. 1968. Least-squares fitting of a straight line. Canad. J. Phys., 46:1845-1847.

Quando os geólogos apalachianos, alpinos, andeanos, do Atlas, ou de Aldan foram ao campo, em novas regiōes, as interpretaçöes que fizeram destas áreas foram compreensivelmente carregadas das visōes reveladas quando a névoa se desvaneceu. [N.E.: O autor refere-se à época em que progressos locais foram alcançados no conhecimento geológico dessas áreas-natais]. Elas não foram geradas em inocência.

MANUSCRITO 528

Recebido em 23 de março de 1988 Revisão aceita em 26 de maio de 1988 